\title{
Pilomatrixoma of the Neck/Shoulder Region Mimicking a Rapidly Growing Neoplasm of Peripheral Nerve Sheath Origin in Neurofibromatosis Type 1
}

\author{
REINHARD E. FRIEDRICH ${ }^{1}$, ULRICH SCHÜLLER ${ }^{2,3,4}$ and CHRISTIAN HAGEL ${ }^{2}$ \\ ${ }^{1}$ Oral and Craniomaxillofacial Surgery, ${ }^{2}$ Institute of Neuropathology, \\ ${ }^{3}$ Department of Pediatric Hematology and Oncology, ${ }^{4}$ Research Institute Children's Cancer Center Hamburg, \\ Eppendorf University Hospital, University of Hamburg, Hamburg, Germany
}

\begin{abstract}
Neurofibromatosis type 1 (NF1) is an autosomal dominant hereditary disorder. Neurofibroma is the most common neoplasm of this disease. This lesion is characterized by circumscribed soft or knotty skin tumors derived from peripheral nerve sheath cells. Numerous other neoplasms have been described for this tumor predisposition syndrome. This case report adds the diagnostic and therapeutic procedures in the case of an NF1 patient in whom the rapidly growing, nodular, subcutaneous tumor initially led to the suspicion of a malignant neoplasm. The tumor proved to be pilomatrixoma, which closely adhered to a neurofibroma.
\end{abstract}

Neurofibromatosis type 1 (NF1) is an autosomal dominant hereditary disorder. NF1 is considered the most common phakomatosis (1). 'Phakomatoses' is an umbrella term for multisystem disorders that have characteristic lesions of the central and peripheral nervous system, and skin of variable severity. NF1-affected individuals particularly develop neoplasms arising from nerve sheath cells (1). Indeed, NF1 is classed as a tumor predisposition syndrome (2) and is regarded as the most frequent hereditary disorder with a predisposition for developing cancer (3). Perhaps the most feared complication for patients with NF1 is the development of malignant peripheral nerve sheath tumors (MPNSTs). About every second patient who develops an MPNST is affected by NF1 $(1,4)$. However, MPNST is a very rare tumor (1). Plexiform neurofibromas (PNFs) are regarded as a precancerous stage in MPNST development $(5,6)$.

Correspondence to: Professor R.E. Friedrich, MD, DMD, FEBOMFS, MKG-Chirurgie, UKE, Martinist. 52, 20246 Hamburg, Germany. Tel: +49 40741053259, e-mail: rfriedrich@uke.de

Key Words: Neurofibromatosis type 1, peripheral nerve sheath tumor, malignant peripheral nerve sheath tumor, pilomatrixoma.
Prognosis of patients with MPNST is poor $(4,7)$. Radical surgery in early stages of the disease provides the best treatment results (8). Rapid growth of a tumor and newly developed pain in a defined area are the most prominent findings that should alert the clinician to search for neoplastic disease in NF1-affected individuals (9). However, these findings are non-specific. Here, we report on a patient with NF1 who developed a tumor in a short time and who was surgically treated. Histology of the tumor provided an unexpected diagnosis.

\section{Case Report}

The 21-year-old female was admitted to the Department of Oral and Craniomaxillofacial Surgery for treatment of a tumor of the left neck/shoulder region that had developed a few months previously. The patient was known to be affected by NF1 (10) and was mentally handicapped. The family history did not give any indication of NF1-affected ancestors. Physical examination of the patient revealed multiple café-au-lait spots of the skin distributed all over her body, axillary freckling, and multiple cutaneous neurofibromas. Facial appearance was characterized by a broad nose, enlarged inter-orbital distance and prominent forehead (11). A prominent and firm tumor was palpable on her left shoulder in the transition area to the neck. The skin covering the tumor was intact, but of diffuse red color (Figure 1C). Palpation of the space-occupying lesion was painless. The tumor adhered to the covering skin but was moveable above the tissue below.

Imaging. B-Scan ultrasound revealed an ovular, encapsulated tumor localized below the skin. The tumor showed dense intralesional inhomogeneous hyperechoic structure with distal enhancement of ultrasound transmission. The so-called target sign of nodular neurofibroma (12) was missing (Figure 1D). The maximum 
diameter of the lesion was $4.5 \mathrm{~cm}$. On the ultrasound images, there were no strand-like structures in the vicinity of the tumor which could be traced to the tumor. The ultrasonographic findings showed no evidence of a tumorous enlarged nerve with intermittent nodular distension. The ultrasound findings were in accordance with the presumption of a solitary nerve sheath tumor, without specifying the biological properties of the suspected neoplasm. The parents of the patient provided a magnetic resonance image (MRI) of their daughter's head and neck region that had been performed 4 years earlier. The MRI disclosed a subcutaneous, ovular lesion of the left neck and shoulder region, approximately in the area of the present space-occupying lesion (Figure 1A and B). This lesion was hyperintense on $\mathrm{T} 2$-weighted images and indicated a subcutaneously located nodular neurofibroma. Compared to the current findings, the original tumor was somewhat further cranially localized, and significantly smaller in diameter, so that the images also confirmed tumor progression in this region.

Therapy. Synopsis of clinical findings led to the decision to remove the tumor promptly. Under general anesthesia, the tumor with covering skin and safety margin of about $1 \mathrm{~cm}$ was completely excised. The defect was closed by primary intention. Wound healing was uneventful.

Pathology. The specimen comprised of a soft biconvex skin sample measuring $6 \times 3 \times 3.5 \mathrm{~cm}^{3}$, which contained an oval, sharply demarcated firm lesion of $2.1 \times 3.3 \times 4.5 \mathrm{~cm}^{3}$. Upon histological investigation, a well-circumscribed tumor in the subcutaneous tissue was observed, which was composed of solid sheets of round inconspicuous squamous epithelial cells with round nuclei and some odd mitoses. Large areas appeared necrotic with eosinophilic ghost-like cells that frequently showed fine granular calcification. Adjacent to the necrotic foci, scattered lymphocytes and numerous multinucleated giant cells of the foreign body type were noted. Separately from the pilomatrixoma, an intraneuronal plexiform neurofibroma was observed in the subcutaneous tissue (Figure 2).

\section{Discussion}

This report describes the diagnostics and surgical therapy of a patient with a tumor predisposition syndrome who had developed a rapidly growing tumor that was suspected to be a malignant tumor originating from peripheral nerve sheath cells. Surprisingly, the histological examination showed a neoplasm of the skin appendages as the main component of the tumor to which a neurofibroma was attached. We assume that the rapidly developing pilomatrixoma had come in close contact with the nerve sheath tumor already displayed on the MRI some years before, thus giving the first impression of a hybrid tumor.

To the best of our knowledge, a pilomatrixoma in the context of an NF1-affected individual has not been reported before. The only other report on a pilomatrixoma with possible association with NF1 is of a young individual with this skin tumor whose relatives were apparently affected with NF1. However, the patient of that report was not described as also being affected by the disease (13).

Pilomatrixoma is only rarely diagnosed in the phacomatoses: A report describes the diagnosis of a pilomatrixoma associated with the initial diagnosis of tuberous sclerosis (14). Another report is on the diagnosis of pilomatrixoma associated with a case of multiple epidermal nevi (15).

Pilomatrixoma is derived from the hair matrix. The entirely benign lesion is a palpatorically hard skin tumor which is found especially in children and adolescents, but also in all other age groups (16-18). The head and neck regions are preferentially the site of origin in this entity (16). From literature comparison, it appears that the occurrence of the skin tumor in a patient with this specific genetic disposition is probably random. However, correct differential diagnosis is of considerable importance to the patient. Diagnosis of pilomatrixoma can cause difficulties. Indeed, the rate of correct first diagnosis of pilomatrixoma apparently is not very high, being reported in the range from about 30 to $70 \%$ (16-18).

Ultrasound examination is very suitable for the initial examination of this skin tumor (19). Lin et al. revealed predominant hypoechoic lesions on ultrasound images of pilomatrixoma. The tumor may show ossifications that can be detected in ultrasound (19). In the present case, the tumor was of dense internal hyperechoic signals and showed a distinct border.

In rare cases, pilomatrixoma occurs as a hybrid lesion $(20,21)$. For example, Terada reported on a mixed pilomatrixoma/epithelial cyst lesion with increased Ki67 expression that also expressed p53 (20). Although the follow-up is incomplete in our case for the purpose of a definitive assessment of the tumor biology, the findings indicate that the two tumors were growing together due to the rapid growth of the pilomatrixoma. Mitotic indices of the lesions were low.

Siah et al. reported on giant exophytic growth of pilomatrixoma of the shoulder (22). Their description of the neoplasm indicates that the tumor can spread in different layers of the skin. Safety margins of 1-2 cm appear to be sufficiently wide to prevent local recurrence and are recommended for large lesions (>5 cm) (22). Malignant transformation of pilomatrixoma was reported (23). Surveillance of the local findings is indicated after surgical treatment of the benign tumor, in particular taking into account the patient's genetic background. 

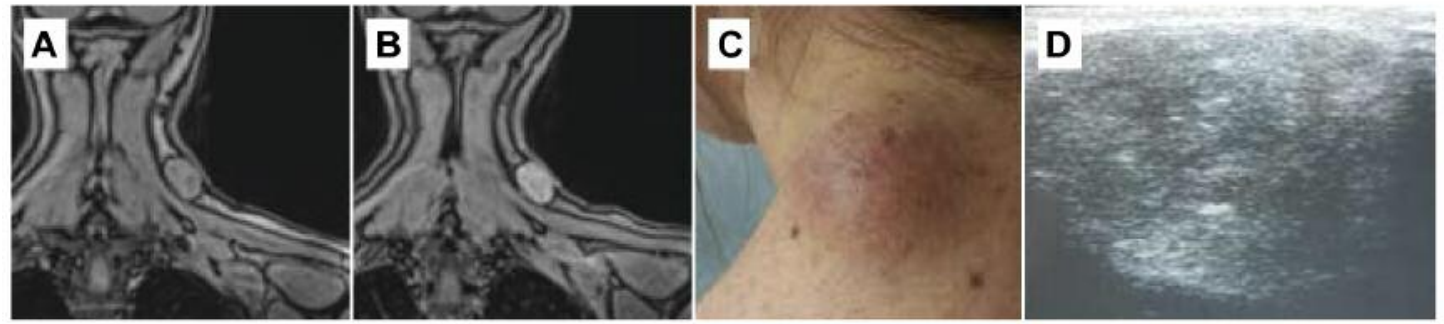

Figure 1. Magnetic resonance imaging (cropped images) of the left shoulder and neck region recorded 4 years before surgical treatment. A: The T1-weighted image shows the oval tumor, the signals of which are isointense relative to the skin. B: The lesion shows a displacing growth pattern. Hyperintense lesion on T2-weighted image. C: Clinical aspect of the left shoulder and neck region at the time of admission. D: B-Scan ultrasound image of the lesion.
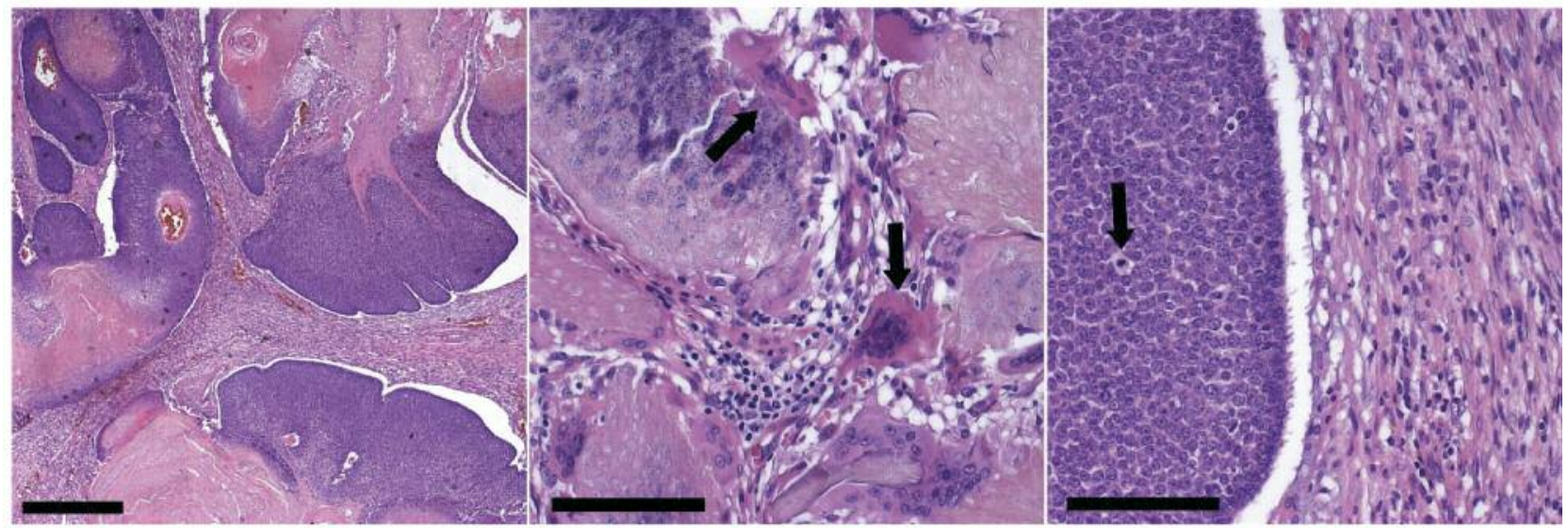

Figure 2. Histopathology of pilomatrixoma. Left: Solid sheets of basaloid cells with bland, round nuclei neighboring areas of 'ghost cells' with eosinophilic cytoplasm. Middle: Magnified view showing multinucleated giant cells (arrows) and sparse lymphocytic infiltrates adjacent to sheets of ghost cells. Right: Magnified view showing vital tumor cells and mesenchymal stroma, note the mitosis in the tumor tissue (arrow) (hematoxylin and eosin stain, scale bars $500 \mu \mathrm{m}$ and $100 \mu \mathrm{m}$, respectively).

\section{Conclusion}

Rapidly growing tumors in patients with NF1 should be promptly diagnosed and treated. In NF1, pilomatrixoma is a very unusual finding, other more frequent neoplasms are to be expected.

\section{References}

1 Scheithauer BW, Woodruff JM and Erlandson RA: Tumors of the Peripheral Nervous System (AFIP Atlas of Tumor Pathology). American Registry of Pathology, Washington DC, 1999.

2 Patil S and Chamberlain RS: Neoplasms associated with germline and somatic NF1 gene mutations. Oncologist 17: 101-116, 2012.

3 Upadhyaya M: Neurofibromatosis type 1: diagnosis and recent advances. Expert Opin Med Diagn 4: 307-322, 2010.

4 Le Guellec S, Decouvelaere AV, Filleron T, Valo I, Charon-Barra C, Robin YM, Terrier P, Chevreau C and Coindre JM: Malignant peripheral nerve sheath tumor is a challenging diagnosis: a systematic pathology review, immunohistochemistry, and molecular analysis in 160 patients from the French Sarcoma Group Database. Am J Surg Pathol 40: 896-908, 2016.

5 Zheng H, Chang L, Patel N, Yang J, Lowe L, Burns DK and Zhu Y: Induction of abnormal proliferation by non-myelinating Schwann cells triggers neurofibroma formation. Cancer Cell 13: 117-128, 2008.

6 Beert E, Brems H, Daniëls B, De Wever I, Van Calenbergh F, Schoenaers J, Debiec-Rychter M, Gevaert O, De Raedt T, Van Den Bruel A, de Ravel T, Cichowski K, Kluwe L, Mautner V, Sciot $\mathrm{R}$ and Legius $\mathrm{E}$ : Atypical neurofibromas in neurofibromatosis type 1 are premalignant tumors. Genes Chromosomes Cancer 50: 1021-1032, 2011.

7 Hagel C, Zils U, Peiper M, Kluwe L, Gotthard S, Friedrich RE, Zurakowski D, von Deimling A and Mautner VF: Histopathology and clinical outcome of NF1-associated $v s$. sporadic malignant peripheral nerve sheath tumors. J Neurooncol 82: 187-192, 2007.

8 Ferner RE and Gutmann DH: International consensus statement on malignant peripheral nerve sheath tumors in neurofibromatosis. Cancer Res 62: 1573-1577, 2002. 
9 Preston FW, Walsh WS and Clarke TH: Cutaneous neurofibromatosis (Von Recklinghausen's disease); clinical manifestation and incidence of sarcoma in 61 male patients. AMA Arch Surg 64: 813-827, 1952.

10 Gutmann DH, Aylsworth A, Carey JC, Korf B, Marks J, Pyeritz RE, Rubenstein A and Viskochil D: The diagnostic evaluation and multidisciplinary management of neurofibromatosis 1 and neurofibromatosis 2. JAMA 278: 51-57, 1997.

11 Mautner VF, Kluwe L, Friedrich RE, Roehl AC, Bammert S, Högel J, Spöri H, Cooper DN and Kehrer-Sawatzki H: Clinical characterization of 29 neurofibromatosis type-1 patients with molecularly ascertained 1.4 Mb type-1 NF1 deletions. J Med Genet 47: 623-630, 2010.

12 Lin J, Jacobson JA and Hayes CW: Sonographic target sign in neurofibromas. J Ultrasound Med 18: 513-517, 1999.

13 Eizaguirre I, Lertxundi M, López Alonso G, Barriola M and Tovar JA: Pilomatrixoma: a frequent and little known pediatric tumor. An Esp Pediatr 20: 412-416, 1984 (in Spanish).

14 Resende CI, Gomes J, Duarte Mda L and Brito C: Giant pilomatricoma in a patient with tuberous sclerosis, both diagnosed in the adult life. BMJ Case Rep, 2013. doi: 10.1136/bcr-2013-010382.

15 Johnson LM and Newell B: Multiple large pilomatricomas in the setting of diffuse epidermal nevi. Pediatr Dermatol 28: 74-76, 2011.

16 Fernández Atuan R, Álvarez García N, González Ruiz Y, Siles Hinojosa A, Rihuete Heras MA and Elías Pollina J: The diagnosis of pilomatrixoma in children is not as easy as it may seem. A review of 126 cases. Cir Pediatr 30: 46-49, 2017.
17 O'Connor N, Patel M, Umar T, Mcpherson DW and Ethunandan M: Head and neck pilomatricoma: an analysis of 201 cases. $\mathrm{Br}$ J Oral Maxillofac Surg 49: 354-358, 2011.

18 Schwarz Y, Pitaro J, Waissbluth S and Daniel SJ: Review of pediatric head and neck pilomatrixoma. Int $J$ Pediatr Otorhinolaryngol 85: 148-153, 2016.

19 Lin SF, Xu SH and Xie ZL: Calcifying epithelioma of malherbe (pilomatrixoma): Clinical and sonographic features. J Clin Ultrasound, 2017. doi: 10.1002/jcu.22517. [Epub ahead of print]

20 Terada T: Cutaneous hybrid tumor composed of epidermal cyst and cystic pilomatricoma expressing p53 and high Ki-67 labeling. Int J Clin Exp Pathol 6: 1187-1189, 2013.

21 Pujani M, Agarwal S, Goyal RK, Jyotsna PL, Tejwani N and Rautela A: Pilomatricoma coexistent with epidermal cyst. Int J Dermatol 51: 624-625, 2012.

22 Siah TW, Rahim RR, Husain A and Langtry JA: A giant lump on the shoulder. Int J Dermatol 54: 255-257, 2015.

23 Otero MN, Trujillo CP, Parra-Medina R and Morales SD: Metastatic malignant pilomatrixoma in an 8-year-old girl misdiagnosed as a recurrent pilomatrixoma. Am J Dermatopathol 39: e41-e43, 2017. 